\title{
EL ESTATUTO DE PERSONAL DE LAS CÁMARAS PARLAMENTARIAS Y SU CONTROL JURISDICCIONAL
}

\author{
ESPERANZA GÓMEZ CORONA \\ Becaria de Investigación F.P.I. \\ Departamento de Derecho Constitucional \\ Universidad de Sevilla
}




$$
\text { . }
$$




\section{EL ESTATUTO DE PERSONAL DE LAS CÁMARAS PARLAMENTARIAS Y SU CONTROL JURISDICCIONAL*}

POR

\section{ESPERANZA GÓMEZ CORONA}

Becaria de Investigación F.P.I. Departamento de Derecho Constitucional Universidad de Sevilla

El artículo 72 de la Constitución contempla, junto a los Reglamentos de las Cámaras parlamentarias y al Reglamento de las Cortes Generales, el Estatuto de Personal, que viene así a configurar la última manifestación de la potestad autonormadora de las Cortes que el mismo precepto constitucional consagra. En concreto, el citado 72.1 CE establece que las Cámaras, de común acuerdo, regulan el Estatuto de Personal de las Cortes Generales.

La mención constitucional a esta norma obedece a una de las manifestaciones del principio de autonomía del que gozan las Cámaras parlamentarias en nuestro sistema constitucional: la autonomía administrativa y concretamente a una faceta de ésta, la autonomía de personal, manifestación que goza de cierta tradición en España. De hecho, el Parlamento ha dispuesto históricamente de su propia estruc-

* Quisiera agradecer al Prof. Dr. D. José María Morales Arroyo sus sugerencias y observaciones, que me han resultado de gran ayuda para la elaboración de este trabajo. 
tura organizativa de personal, regida por reglas formalmente distintas a las imperantes en el aparato burocrático de la Administración Pública. En este sentido, se ha llegado a reconocer uuna vieja tradición que excluye a los funcionarios de los Cuerpos colegisladores del régimen estatutario de la Función Pública general", y asi, desde la ley de 9 de julio de 1885, se excluyó del principio de incompatibilidad, en cuanto a percibir más de un sueldo de los Presupuestos Generales del Estado, a los funcionarios parlamentarios que hubiesen obtenido el cargo en propiedad'.

En la vigente Constitución, esta autonomía de personal, que supone la existencia de un personal propio de las Cámaras, formando un cuerpo separado del resto de funcionarios tiene, según GarcíaEscudero, un doble fundamento, teórico y práctico. El fundamento teórico deriva, como no podía ser de otro modo, del principio de separación de poderes. Con la existencia de este personal propio de las Cortes, distinto del de la Administración que, como es sabido, depende en última instancia del Gobierno, se pretende preservar la autonomía e independencia parlamentaria ${ }^{2}$. El fundamento práctico radica, en cambio, en la conveniencia de que, dada la especial naturaleza del trabajo parlamentario, exista un personal funcionario con una cualificación específica ${ }^{3}$.

En lo que respecta a las Asambleas Parlamentarias de las Comunidades Autónomas, únicamente algunos Estatutos de Autonomía contemplan la figura del Estatuto de Personal al servicio de la Asamblea ${ }^{4}$. Sin embargo, todas ellas han aprobado una norma de este tipo, basándose en una previsión del Reglamento de la Cámara cuando el Estatuto de Autonomía no contenía ninguna alusión al respecto ${ }^{5}$. Más tarde, dada la singularidad de tal proceder, volveremos sobre este asunto.

1 GarRIDo Falla, F., «La Administración parlamentaria", en I Jornadas de Derecho Parlamentario, vol. I (Madrid, Congreso de los Diputados, 1985), pág. 104.

2 Sin embargo, hay que destacar cómo en la práctica, el régimen de incompatibilidades que el propio Estatuto establece es bastante flexible (artículos 38 a 45 EPCG).

3 García-Escudero Márouez, P., «Artículo 72.1 CE. Autonomía funcional de las cámaras: reglamentaria, presupuestaria y de personal», en ALZAGA, O., Comentarios a la Constitución Española de 1978, tomo VI (Madrid, Edersa, 1998), pág. 423.

4 Éste es el caso de los Estatutos de Autonomía del País Vasco (arts. 27.1,III), de Asturias (art. 28.1), Murcia (art. 27.1), Aragón (art. 14.1), Castilla y León (art. 13.4) y La Rioja (art. 18.3).

5 Así ha ocurrido en los Parlamentos de Andalucía y Castilla-La Mancha. 


\section{EL ESTATUTO DE PERSONAL DE LAS CORTES GENERALES: NOTAS CONSTITUCIONALES}

La Constitución otorga a las Cámaras parlamentarias la facultad de dictar las normas según las cuales se regirá todo el personal a su servicio. Pero la Carta Fundamental, en el breve enunciado del artículo $72.1 \mathrm{CE}$, va a imponer algunos condicionamientos.

En primer lugar, como ya se ha señalado, ha de ser un personal dependiente únicamente de las Cortes Generales, conformando un cuerpo separado del resto del funcionariado al servicio de las Administraciones Públicas, para evitar así injerencias, fundamentalmente del Gobierno, que se sitúa al frente de todo el aparato administrativo del Estado.

En segundo lugar, ese personal ha de ser común a las dos Cámaras, constituyendo una excepción al principio de autonomía, que se predica de cada Cámara individualmente considerada. Esto supone una novedad en lo que a la autonomía parlamentaria se refiere, ya que sus otras manifestaciones, esto es, la potestad de establecer su Reglamento, de aprobar el propio Presupuesto o de elegir a sus órganos de gobierno, se ejercen por cada Cámara por separado. Algunos autores, como Alzaga, han entendido que la causa de esta peculiaridad radica en el tránsito de las Cortes orgánicas del régimen anterior a unas bicamerales sin solución de continuidad 6 .

En tercer lugar, la Constitución establece que el Estatuto debe ser regulado "de común acuerdo" por ambas Cámaras ${ }^{7}$. Esta exigencia constitucional ha provocado cierta polémica entre la doctrina, puesto que, según veremos más adelante, el Estatuto ha sido en la práctica aprobado por las Mesas de ambas Cámaras en reunión conjunta, órgano de dudosa naturaleza, ya que se trata más bien de la reunión de dos órganos parlamentarios distintos.

6 La Constitución Española de 1978, comentario sistemático (Madrid, Ediciones del Foro, 1978), pág. 506.

7 En el procedimiento de elaboración de la Constitución se incluyó la referencia expresa al Estatuto de Personal de las Cortes desde el primer momento. EI texto no sufriría alteraciones hasta la última fase. Es la Comisión Mixta la que, sin que el Senado hubiera hecho propuesta alguna de variación, incorpora la exigencia del común acuerdo de las Cámaras para la aprobación del Estatuto, que pasa a la redacción del definitivo artículo 72 de la Constitución, vid. Dictamen de la Comisión Mixta Congreso-Senado sobre el Proyecto de Constitución, BOCG de 28 de octubre de 1978, n. ${ }^{\circ} 170$. 
El silencio constitucional en torno al procedimiento de aprobación del Estatuto del Personal, ha desatado la especulación de la doctrina sobre la forma en que dicha aprobación debía llevarse a cabo. Así, para Punset, la solución más adecuada consiste en un procedimiento de iniciativa autónoma y alternativa y de aprobación sucesiva ${ }^{8}$ En el mismo sentido se manifiesta Elviro Aranda ${ }^{9}$ y Díez-Picazo; éste último entiende que para la aprobación del Estatuto de Personal de común acuerdo por ambas Cámaras, asi como para la aprobación por mayoría absoluta de cada Cámara del Reglamento de las Cortes Generales, "la autonomía parlamentaria debe ser ejercida a través de sendos actos de cada Cámara que, para perfeccionarse, han de ser idénticos y convergentes" 10 .

La aceptación de esa construcción como punto de partida ha dado lugar a que autores como López Muñiz consideren que el Estatuto de Personal de las Cortes, en cuanto dictado por las Mesas del Congreso y del Senado en sesión conjunta, se debe definir como una norma meramente administrativa, privada del valor y de la fuerza que, en principio, sólo poseen las normas dictadas o aprobadas por los únicos órganos titulares de la potestad legislativa, las Cámaras, en Pleno o, en su caso, a través de las correspondientes Comisiones legislativas. Este autor va incluso más lejos con la afirmación de que el Estatuto ha incurrido en nulidad de pleno derecho o invalidez absoluta" De igual modo, Mollinedo Chocano entiende que el Estatuto de Personal, tal y como ha sido aprobado, constituye una norma reglamentaria, con la peculiaridad de proceder de las Cortes Generales y que, en todo caso, representa un reglamento independiente al no encontrarse sometido a ninguna ley, sino directamente a la Constitución ${ }^{12}$. Coincide por último en esta opinión Santaolalla, cuando critica la postura asumida por el Tribunal Constitucional sobre esta materia ${ }^{13}$. pág. 86.

8 Las Cortes Generales (Madrid, Centro de Estudios Constitucionales, 1983),

9 Los actos parlamentarios no normativos y su control jurisdiccional (Madrid, Centro de Estudios Politicos y Constitucionales, 1998), pág. 359.

10 La autonomía administrativa de las Cámaras parlamentarias (Zaragoza, Cuadernos de los Studia Albornotiana, 1985), pág. 29.

11 "Consideraciones sobre el Estatuto del Personal de las Cortes Generales: reserva legal y administración parlamentarian, en / Jornadas de Derecho Parlamentario, vol. II, op. cit., pág. 682 .

12 «EI personal al servicio de las Cámaras en la jurisprudencia constitucional -aproximación al régimen constitucional de la función pública parlamentaria-", en PAU I VALL (coord.), Parlamento y Justicia Constitucional (Pamplona, Aranzadi, 1997), pág. 443.

${ }_{13}$ Derecho Parlamentario Español (Madrid, Espasa-Calpe, 1990), pág. 54. 
Ciertamente, de la dicción literal de la Constitución parece deducirse que han de ser las Cámaras, entendiéndose esta afirmación referida al Pleno, las que aprueben el Estatuto y no las Mesas, que no tienen por qué reflejar necesariamente la correlación de fuerzas existentes en la Cámara ${ }^{14}$. El hecho de que el artículo 72 de la Carta Magna distinga entre el procedimiento de elaboración de los Reglamentos y el del Estatuto se debe, a mi juicio, a que para la aprobación de este último, no es exigible la mayoría absoluta necesaria para los Reglamentos.

No obstante, para García-Escudero tiene un cierto sentido el hecho de que «una norma que afecta a la faceta administrativa de las Cámaras y no a la parlamentaria (entendida como el ejercicio de las funciones constitucionales), sea aprobada por sus órganos rectores, las Mesas, de las que se ha señalado su carácter de bisagra entre el poder legislativo y la Administración parlamentaria, en su doble condición de órganos administrativos y parlamentarios" 15. Además, como ha expresado Santaolalla, el Estatuto de Personal de las Cortes Generales no forma parte del Derecho Parlamentario, pues sólo incide en materias organizativas y funcionariales, administrativas por tanto, alejadas de las funciones políticas que como cuerpos representativos corresponden a las Cámaras ${ }^{16}$.

Pero no sólo la aprobación del Estatuto, sino también sus sucesivas reformas se han realizado mediante Acuerdo conjunto de ambas Mesas ${ }^{17}$. Por lo demás, el Tribunal Constitucional, que tuvo ocasión en 1988 de pronunciarse sobre este punto, aunque de manera colateral,

14 García-Escudero sostiene que según el tenor literal del artículo 72.1 de la Carta Magna, los órganos competentes para la elaboración del Estatuto son los Plenos. «Art. 72.1, Autonomía funcional de las Cámaras: reglamentaria, presupuestaria y de personal", op. cit., pág. 424.

15 Piedad Garcia-Escudero, op. cit., pág. 425.

16 Derecho Parlamentario Español, op. cit., pág. 53. Punset, en el mismo sentido, señala que el Estatuto no opera como norma de desarrollo del artículo 66.2 CE y sus preceptos complementarios, sino como expresión de una autonomía de carácter doméstico. "Los Reglamentos de las Cortes Generales", Revista de Derecho Público, 87(1982), pág. 344.

17 En efecto, tanto el Estatuto de 23 de junio de 1983 como el actualmente vigente, de 26 de junio de 1989 han sido aprobados por reunión conjunta de las Mesas del Congreso de los Diputados y del Senado. Las posteriores modificaciones al Estatuto hoy en vigor también han sido aprobadas de igual forma (modificaciones de 17 de enero de 1991, de 28 de noviembre de 1994, de 11 de julio de 1995, de 28 de junio de 1996, de 31 de diciembre de 1996 y de 17 de julio de 1997). 
dado que el origen del proceso lo constituía un recurso de amparo, ha admitido la constitucionalidad de esta práctica ${ }^{18}$.

Una vez visto que la Constitución impone la exigencia de que el personal al servicio de las Cortes sea un personal propio, que ha de ser además común a ambas Cámaras y que la norma que regule esta cuestión ha de ser aprobada "de común acuerdo" por el Congreso de los Diputados y el Senado, vamos ahora a analizar un par de cuestiones intimamente relacionadas con la regulación constitucional del Estatuto de Personal: a) su carácter de norma primaria y b) la existencia de una reserva de Estatuto.

Sobre la primera cuestión hay que afirmar, con López Guerra, que nos encontramos ante una norma primaria, que no admite otro contraste a efectos de verificar su validez que no sea con la norma constitucional. Por ello, cabe hablar de inconstitucionalidad del Estatuto, pero no de ilegalidad ${ }^{19}$. Esto se debe a que la Constitución le encomienda de forma directa la regulación de la materia relativa al personal al servicio de las Cortes Generales. Un elemento que ha permitido a parte de la doctrina hablar de la fuerza de ley del Estatuto, ya que desarrolla la Constitución en la materia objeto de su competencia de forma primaria y directa, sin intermediarios. $Y$ en esta cuestión, Mollinedo Chocano ha entendido que el Estatuto, en tanto que fruto de la autonomía de personal de las Cortes Generales, no está condicionado por ninguna otra norma, salvo por la propia Constitución y en particular, por los principios constitucionales en materia de función pública que en la misma se contienen. Pero, aparte de este condicionamiento constitucional, las Cortes Generales disfrutan de absoluta libertad para la regulación del régimen jurídico de su personal20.

En cuanto a la segunda cuestión, la doctrina parece tener clara la premisa de que existe una reserva de Estatuto, lo que conlleva que ninguna otra norma puede entrar a regular las cuestiones que conforman su objeto propio. En cuanto al contenido y la extensión de esta reserva, Punset apunta que su propia denominación evidencia la materia que están llamados a regular y que es idéntica a la que, para los funcionarios de la Administración pública, define el artículo 103.3 CE

18 STC 139/1988, de 8 de julio.

19 "El control del Derecho Parlamentario", en Silva OCHOA, Las fuentes del Derecho Parlamentario (Vitoria-Gasteiz, Parlamento Vasco, 1996), pág. 295.

20 «El personal al servicio de las Cámaras en la jurisprudencia constitucional - aproximación al régimen constitucional de la función pública parlamentaria - ", en Parlamento y Justicia Constitucional, op. cit., pág. 433. 
como objeto de reserva de ley ${ }^{21}$ : estatuto de los funcionarios, acceso a la función, sindicación, incompatibilidades y garantías para su imparcialidad 22 .

Pues bien, al igual que ha ocurrido con los Reglamentos Parlamentarios, el hecho de entender que el Estatuto es una norma primaria, unido a la existencia de una reserva de Estatuto en la Constitución, ha llevado a la doctrina y alTribunal Constitucional, como más adelante podremos comprobar, a sostener que el Estatuto tiene fuerza de ley. Al menos, el Estatuto tal y como lo configura la Constitución, ya que no son pocos los autores que entienden que su aprobación por las Mesas de las Cámaras priva del carácter de fuerza de ley de que gozaría si hubiera sido aprobado por los Plenos. En este sentido, López Muñiz, como ya apuntamos, disiente de la forma en que el Estatuto ha sido aprobado, debido a que entiende que la aprobación del mismo es competencia exclusiva del Poder legislativo de la Cámara y no de la Administración parlamentaria. Sólo esta forma de aprobación es coherente, según el autor, con la reserva legal que el artículo $103 \mathrm{del}$ texto constitucional determina en relación con el estatuto de los funcionarios públicos, el acceso a la función pública de acuerdo con los principios de mérito y capacidad, las peculiaridades del ejercicio de su derecho a sindicación, el sistema de incompatibilidades y las garantías para la imparcialidad en el ejercicio de sus funciones, sencillamente porque el artículo 103 de la Constitución se considera por la doctrina, aplicable a todas las Administraciones del Estado, no sólo a la gubernativa, a pesar de estar insertado en el título IV, que se refiere más directamente a aquélla. No tendría sentido que los funcionarios de la Administración Parlamentaria quedaran privados de la garantía que supone la reserva de la regulación de sus relaciones con la Administración a la ley, a la decisión del Parlamento ${ }^{23}$. Además, la Constitución establece una reserva de ley en relación con el derecho de acceso en condiciones de igualdad a las funciones $y$ cargos públicos (artículos 23.2 y $53.1 \mathrm{CE}$ ), reserva incluso de ley orgánica (artículo 81.1 CE). En el ámbito de este derecho quedaría comprendida la regulación del estatuto de los funcionarios de las Asambleas legislativas.

21 «La posición de los Reglamentos Parlamentarios en el ordenamiento español", en SiLVA OCHOA, Las fuentes del Derecho parlamentario, op. cit., pág. 76.

22 García EsCUdERO, P.: "Art. 72.1, autonomía funcional de las Cámaras: reglamentaria, presupuestaria y de personal", op. cit., pág. 426.

23 «Consideraciones sobre el Estatuto de Personal de las Cortes Generales: reserva legal y administración parlamentarian, en I Jornadas de Derecho Parlamentario, op. cit., pág. 680 . 
En conexión con este asunto surge una cuestión de gran trascendencia. El Estatuto de Personal de las Cortes Generales (en adelante EPCG), como norma reguladora de todo lo concerniente al personal al servicio de las Cámaras, puede contener disposiciones relativas al derecho de sindicación, que según el texto constitucional constituye materia propia de ley orgánica (artículos 81 y 53.2 CE). Por tanto, debemos plantearnos si la autonomía normativa de las Cámaras concede título suficiente a éstas para desatender la reserva de ley orgánica establecida en la Constitución. En principio, habría que afirmar que, dada la expresa reserva a esta norma contenida en la Constitución y su carácter de lex specialis en este punto, el artículo 72 CE sí ofrece la cobertura necesaria para entender constitucional esta situación. Lo que ocurre es que, como venimos censurando, el Estatuto, en tanto que aprobado por las Mesas del Congreso y del Senado, no parece norma suficiente para contener una cuestión como ésta. Si el Pleno de cada Cámara hubiera participado en su aprobación, como del espíritu del artículo 72 CE se desprende, podríamos afirmar que, a pesar de la reserva de ley orgánica en materias como el derecho de sindicación, la autonomía parlamentaria, en cuanto que constitucionalmente prevista, permite la regulación en esta otra norma. Por lo demás, tampoco veríamos desatendida la reserva de ley que exige la Constitución en materia de funcionarios. Por tanto, la aprobación del Estatuto por las Mesas plantea numerosos problemas de regularidad constitucional.

Sin embargo, el Tribunal, sin detenerse en estas reflexiones, ha dotado de fuerza de ley al Estatuto, que no puede ser modificado por ninguna otra norma en la materia objeto de su competencia, dada la reserva que la Constitución establece. Un sector doctrinal, a partir de esta premisa ha sostenido que el Estatuto, como norma primaria con fuerza de ley, resulta susceptible de declaración de inconstitucionalidad. El desacuerdo surge, en cambio, cuando se trata de identificar el concreto precepto de la Ley Orgánica del Tribunal Constitucional (en adelante LOTC) que permite tal control. Más adelante volveremos sobre este asunto.

\section{EL ESTATUTO DE PERSONAL DE LAS ASAMBLEAS AUTONOMMICAS}

En el caso de las Comunidades Autónomas, los distintos Estatutos de Autonomía se han convertido en la norma de referencia en la definición del alcance de la autonomía parlamentaria de la que gozan 
sus respectivas Asambleas Legislativas. A este respecto, el Tribunal ha afirmado que:

"La extensión de la autonomia de las Asambleas legislativas de las Comunidades Autónomas viene determinada por el Estatuto de cada una de éstas (ya que no existe, a diferencia de las Cortes Generales, una garantía constitucional al respecto) $/ 24$.

Sin embargo, únicamente seis Estatutos de Autonomía aluden de forma expresa a este tipo de norma, lo que no ha constituido obstáculo para que todas las Cámaras autonómicas sin excepción hayan aprobado una norma por la que se va a regir el estatuto del personal a su servicio ${ }^{25}$. En los demás casos, la previsión para su elaboración aparece en el propio Reglamento Parlamentario de la Asamblea ${ }^{26}$. La diferenciación de origen no tiene una importancia meramente teórica, pues conlleva importantes consecuencias en cuanto a su naturaleza jurídica, ya que si bien es posible predicar el rasgo de primariedad de aquellos Estatutos de Personal expresamente contemplados en el Estatuto de Autonomía de la Comunidad, no podemos decir lo mismo de aquellos cuya previsión aparece en el Reglamento Parlamentario de la Asamblea. La norma reglamentaria no parece ofrecer la cobertura suficiente para la elaboración de una disposición a la cuál, como más adelante podremos comprobar, el Tribunal Constitucional ha reconocido, entre sus elementos definitorios, valor de ley.

De igual forma goza de gran importancia, a mi juicio, el modo de aprobación de esta norma. La mayoría de los Estatutos de Personal autonómicos han sido aprobados por la Mesa de cada Asamblea27, puede que contagiados por el ejemplo del EPCG; $y$ ello a pesar de que sólo en algunos supuestos el precepto que preveía su elaboración encomendaba la tarea a este órgano. Éste ha sido el caso del Parlamento aragonés y de las Cortes de Castilla y León ${ }^{28}$ Algo más curioso

24 STC 179/89, de 2 de noviembre, F.J. Cuarto.

25 Estos Estatutos son los de Asturias, Murcia, País Vasco, Aragón, Castilla y León y La Rioja.

26 A modo de ejemplo señalar la Disposición Adicional Segunda del Reglamento del Parlamento de Andalucía o la Disposición Final Tercera del Reglamento del Parlamento de Cantabria.

27 Estatutos de Andalucía, Aragón, Asturias, Baleares, Castilla-La Mancha, Castilla León, Extremadura, Galicia, Madrid y Valencia.

28 Artículo 29.1.i) del Reglamento de las Cortes de Aragón y Disposición Final Tercera del Reglamento de las Cortes de Castilla y León. 
se presenta el caso de la Asamblea de Madrid, en la que, aun cuando su Reglamento encomienda la aprobación de esta norma al Pleno del Parlamento ${ }^{29}$, ha sido finalmente su Mesa la que así lo ha hecho. En el último caso creo que la evidencia de la extralimitación no requiere excesivas explicaciones y justificaría sobradamente una futura declaración de nulidad de la norma.

El único Parlamento que ha procedido a la aprobación del Estatuto de su Personal por el Pleno ha sido la Diputación General de La Rioja, dando cumplimiento al precepto reglamentario que asi lo disponia ${ }^{30}$. En el resto de las Asambleas han sido distintas Comisiones las que han procedido a la elaboración de esta norma ${ }^{31}$. Así, por ejemplo, en el Parlamento cántabro, el Estatuto ha sido aprobado por acuerdo de la Mesa y de la Comisión de Gobierno.

La delimitación de la norma de cobertura y la determinación del órgano competente para la creación del Estatuto de Personal de una Cámara autonómica tiene una evidente relevancia para la atribución de rango jerárquico a estas normas y para la averiguación del tipo de control que frente a ellas cabe ejercer. ElTribunal Constitucional ha concedido rango de ley al Estatuto de Personal de una Cámara autonómica, el Parlamento navarro. En concreto, en el Auto 296/85, como luego podrá comprobarse, se afirma que el Estatuto de Régimen y Gobierno Interior del Parlamento de Navarra goza de valor de ley. Así pues, si entendemos el pronunciamiento jurisprudencial extensible a todas las normas de personal de los Parlamentos autonómicos, habrá que concluir que el Tribunal Constitucional se convierte entonces en el órgano competente para fiscalizar la constitucionalidad de todos ellos.

Sin embargo, una afirmación de esta naturaleza sobre normas que han sido aprobadas por las respectivas Mesas resulta excesiva. Además, en el caso de los Estatutos de las Cámaras autonómicas nos encontramos con un problema añadido, ya que el fundamento para elaborar una norma como ésta no aparece generalmente en el Estatuto, sino en el propio Reglamento Parlamentario de la Asamblea en cuestión. Según lo visto, sólo seis Estatutos hacen referencia expresa

29 Disposición Final Tercera del Reglamento de la Asamblea.

30 Artículo 141 del Reglamento del Parlamento de la Rioja.

31 La Comisión de Reglamento en el Parlamento canario y en el navarro, donde esta norma tiene rango de Ley Foral por previsión del Reglamento de la Asamblea; la Comisión de Gobierno Interior en los Parlamentos Catalán y Murciano y la de Urgencia Legislativa, Reglamento y Gobierno en el Parlamento vasco. 
a esta norma, mientras que, en los demás casos, es el Reglamento Parlamentario el que ofrece la cobertura necesaria para elaborar una norma que, en muchas ocasiones resulta aprobada por la Mesa de la Asamblea. El cúmulo de circunstancias descrito acaba situando el problema en el respeto o incumplimiento de la reserva legal establecida constitucionalmente en materia de funcionarios. Pero sobre estas ideas profundizaremos más adelante, al analizar la jurisprudencia constitucional recaída en torno a este asunto.

\section{EL CONTROL JURISDICCIONAL DEL ESTATUTO DE PERSONAL}

\subsection{El Estatuto de Personal de las Cortes Generales}

Aunque el Tribunal Constitucional ha entendido que el EPCG, en tanto que norma que goza de valor de ley, es susceptible de control de constitucionalidad por los procedimientos para ello previstos en la LOTC, la falta de alusión al Estatuto en la citada norma, a diferencia de lo que ocurre con los Reglamentos de las Cámaras, plantea algunas cuestiones de gran interés. Para López Guerra, la omisión detectada en la Ley reguladora de la Jurisdicción Constitucional conduce a pensar que, ya que el artículo 9.1 de la Constitución impide la existencia de zonas exentas de control jurisdiccional, debe ser la jurisdicción ordinaria la competente para conocer de la sujeción al ordenamiento del Estatuto de personal de las Cortes, dada la dificultad para fundamentar la inclusión de éste en el elenco de normas susceptibles de declaración de inconstitucionalidad ${ }^{32}$.

Antes de nada, el punto de partida de cualquier reflexión debe situarse en el hecho de que la Constitución no hace mención alguna al control del Estatuto de personal por elTribunal Constitucional, lo que no ha sido escollo para el conocimiento por este órgano. Un silencio similar existia para los Reglamentos Parlamentarios y la propia LOTC, al desarrollar el artículo 161 de la Constitución, ha incluido a los Reglamentos de las Cámaras entre las disposiciones susceptibles de convertirse en objeto de un proceso de control de constitucionalidad, ex artículo 27.2 de la citada Ley Orgánica ${ }^{33}$.

32 "El control del Derecho Parlamentario", en Las fuentes del Derecho Parlamentario, op. cit., pág. 296.

33 A este respecto, véase PARDo FALCÓN, F. J., "Comentario al artículo 27 LOTC", en Requejo PAgés, J. L. (coord.), Comentarios a la Ley Orgánica del Tribu- 
La cuestión estriba en comprobar si el silencio constitucional sobre el control de los Estatutos ha sido soslayado también por alguno de los apartados del artículo 27 de la LOTC. Mención expresa, desde luego, no hay; pero la redacción dada a dos de sus apartados, podría tal vez solucionar el problema exegético: el artículo 27.2 b) alude al control por el Tribunal de las "disposiciones normativas y actos del Estado con fuerza de ley" y el artículo 27.2 d), a "los Reglamentos de las Cámaras y de las Cortes Generales'. Como antes se señalaba, la doctrina se divide entre los que estiman que los Estatutos son susceptibles de ser declarados inconstitucionales por la vía del citado apartado b) y los que entienden que se produce una asimilación a los Reglamentos de las Cámaras ${ }^{34}$.

A mi juicio, el dato decisivo para resolver esta cuestión estriba en la inclusión en la LOTC de las otras normas parlamentarias que se contienen en el artículo 72 de la Constitución, producto, al igual que el Estatuto, del principio de autonomía normativa que a las Cámaras se reconoce. Si el legislador hubiera pretendido someter a control de constitucionalidad el Estatuto de personal, lo habría incluido de forma expresa en el tan citado artículo 27 de la LOTC. A pesar de esto, hay que reconocer que la caracterización de esta norma como de carácter primario, unida a la reserva de materias propias de su regulación, dota a esta norma de unos caracteres tales que la pueden hacer asimilable a las normas con valor de ley y por tanto, susceptible de declaración de inconstitucionalidad por la vía del artículo 27.2.b), como norma con fuerza de ley. Sin embargo, el modo en que la aprobación del EPCG se ha llevado a cabo, por las Mesas del Congreso y del Senado en reunión conjunta, complica algo más la cuestión.

En efecto, como ya se ha señalado más arriba, la aprobación del Estatuto por las Mesas tiene importantes efectos sobre su rango y en consecuencia, sobre el control que frente a él cabe ejercer. Resulta dificil conceder rango de ley a una norma aprobada por las Mesas de las Cámaras, por lo que, a mi juicio, lo más sensato es atribuir a la citada norma valor infralegal y en consecuencia, afirmar su sometimiento a la Jurisdicción ordinaria, en concreto al Orden Contencioso-Adminis-

nal Constitucional (Madrid, Tribunal Constitucional-Boletín Oficial del Estado, 2001), págs. 367-396.

34 Sobre el control del EPCG por la via que ofrece el artículo 27.2 b), LOPEZ MuÑiz y Mollinedo Chocano. Defendiendo su asimilación a los Reglamentos Parlamentarios, esto es, el control por el cauce que establece el artículo 27.2 d), FERNANDO Santaolalla y Jiménez Asensio. 
trativo; sobre todo, tras la redacción de la nueva ley de la Jurisdicción Contencioso-Administrativa, Ley 29/98, de 13 de julio. Esta norma, en su artículo 1.3, a) reconoce la competencia de este orden jurisdiccional para conocer de las pretensiones que se deduzcan en relación con "los actos y disposiciones en materia de personal, administración y gestión patrimonial sujetos al Derecho público adoptados por los órganos competentes del Congreso de los Diputados, del Senado y de las Asambleas Legislativas de las Comunidades Autónomas». Dado que el Estatuto entra dentro de la categoría de disposiciones y se refiere a materia de personal, siendo además adoptado por las Cámaras Legislativas, puede quedar sometido a la Jurisdicción contencioso-administrativa. Únicamente la aprobación por los respectivos Plenos podría haber supuesto el valor de ley de la norma y su sometimiento en consecuencia a la Jurisdicción Constitucional.

Pero esta interpretación no coincide con la que hasta la fecha han venido haciendo elTribunal Constitucional y el Tribunal Supremo, que han considerado el Estatuto como una norma con rango y valor de ley.

ElTribunal Constitucional va a tener ocasión de pronunciarse en extenso sobre la naturaleza jurídica y vías de control del EPCG en la Sentencia 139/88, de 8 de julio, que resuelve un amparo interpuesto por un funcionario en activo de las Cortes Generales contra un Acuerdo de las Mesas del Congreso de los Diputados y del Senado por el que se modificaba el Estatuto de Personal, además de contra la desestimación presunta del recurso de reposición interpuesto contra el citado Acuerdo y finalmente contra la sentencia del Tribunal Supremo que declaraba la inadmisibilidad del recurso contencioso-administrativo. Resulta interesante este pronunciamiento, la STS de 20 de enero de 1987, porque muchas de las afirmaciones delTribunal Supremo las hará luego suyas el Tribunal Constitucional.

En efecto, el Tribunal Supremo desestima el recurso contencioso-administrativo por entender que lo que se impugnaba era un acuerdo «que tiene el valor de una disposición general de rango equivalente a una Ley, al ser una norma reglamentaria que se integra en el Estatuto de Personal de ambas Cámaras, que es una manifestación, insistimos una vez más, de su genérico poder de autoorganización, y que no se puede identificar con un reglamento propiamente dicho, sino, más bien, se trata de una auténtica Ley, en la medida que tales normas reglamentarias proceden de los órganos legislativos y enlazan directamente con la norma constitucional -art. 72.2-, de lo que se infiere, como conclusión, que son normas primarias, sólo justiciables 
ante el Tribunal Constitucional, tal como se establece en el art. 27.2.d) de la Ley Orgánica de dicho Tribunal»35.

Centrándonos ya en la jurisprudencia Constitucional, resulta significativo que en el Fundamento Jurídico segundo se afirme que:

"La Constitución, en su art. 72.1, establece una reserva formal y material a favor del Estatuto de Personal de las Cortes Generales, de manera que ese Estatuto aparece como una norma directamente vinculada a la Constitución, es decir, como una norma primaria - o acto normativo primario - que, por ello mismo, determina que la regulación a él encomendada quede fuera del alcance de cualquier otra norma jurídica. Así pues, el Estatuto de Personal de las Cortes Generales, por imperativo constitucional, goza de una efectiva fuerza de Ley, al menos en su vertiente pasiva, por cuanto que ninguna otra norma del ordenamiento puede proceder a la regulación que a él le ha sido reservada y en exclusiva encomendada por la Constitución».

\section{Y sigue argumentando el Tribunal:}

"El Estatuto del Personal de las Cortes Generales no es equiparable en manera alguna a las normas reglamentarias, ya que, a diferencia de éstas, aquél no se halla subordinado a la Ley, sino directamente incardinado y vinculado a la Constitución. No se trata, en efecto, de una disposición de categoría inferior a la ley, sino, antes bien, de una norma que, de acuerdo con la reserva constitucional establecida, goza de fuerza de ley y que, asimismo, por proceder del Poder Legislativo, posee valor de Ley. Pero puede añadirse también, no obstante, que en nada empece tal conclusión el hecho de que el art. 27.2 de la LOTC no mencione expresamente al Estatuto de Personal de las Cortes, dado que, con cobertura en el artículo $161.1 \mathrm{~d}$ ) de la Constitución entre los supuestos susceptibles de declaración de inconstitucionalidad se incluyen también los actos del Estado con fuerza de ley (art. 27.2 b) de la LOTC); categoria ésta en la que, a los efectos señalados, bien puede subsumirse sin dificultad alguna el referido Estatuto del Personal de las Cortes Generales, obviándose de este modo la aparente laguna de la LOTC y, en su caso, la interpretación un tanto forzada del apartado d) del mismo art. 27.2 que

35 Fundamento Jurídico cuarto, STS de 20 de enero de 1987. El único punto de desacuerdo entre esta argumentación y la que luego efectuará el Tribunal Constitucional, es el relativo al precepto concreto de la LOTC que permite el control del Estatuto. Para el Tribunal Supremo es el artículo $27.2 \mathrm{~d}$ ), ya que asimila la norma estatutaria al Reglamento Parlamentario. ElTribunal Constitucional, en cambio, asimila el Estatuto a las normas con valor de ley y por ello afirma que es el artículo 27.2 b) el que posibilita el control de esta norma. 
en ocasiones se ha tratado de mantener. La Constitución, dada la reserva formal y material que a favor del Estatuto del Personal de las Cortes Generales establece (art. 72.1), da plena cobertura a la calificación de dicha norma, y los Acuerdos que la modifiquen, como disposición con valor y fuerza de ley no susceptible en sí misma de impugnarse, sino a través del recurso de inconstitucionalidad, dejando a salvo, claro es, los casos en que medie una cuestión de inconstitucionalidad o se llegue a plantear autocuestión de inconstitucionalidad de acuerdo con lo dispuesto en el art. 55.2 LOTC».

Por último, en el Fundamento Jurídico tercero hace el Tribunal unas apreciaciones de gran interés:

"La Constitución ha establecido una reserva constitucional de ley para la regulación del Estatuto de los funcionarios públicos y el acceso a la función pública $y$, por imperativo constitucional (art. 72.1 de la Constitución), esa regulación, en el caso de los funcionarios al servicio de las Cortes Generales adoptado de común acuerdo por ambas Cámaras, resulta convincente que ese Estatuto, en cuanto a su posición normativa en el sistema de fuentes, a la ley habrá de equipararse. Si el Estatuto en cuestión fuese una simple norma reglamentaria de categoría inferior a la ley, la propia reserva constitucional de Ley en materia funcionarial quebraría (al menos en relación a los funcionarios al servicio de las Cortes) de manera que, a juicio del Tribunal Supremo - que debe compartirse -, la estricta lógica del sistema aboca a que el Estatuto del Personal de las Cortes Generales no pueda ser calificado como norma de categoria inferior a la ley. El juego combinado de la reserva constitucional formal de Ley en materia de funcionarios y la propia reserva constitucional material para proceder a la regulación del Estatuto del Personal al servicio de las Cortes a una norma específica y singular asi llamada precisamente, imposibilita, en definitiva, la equiparación de ese Estatuto con las normas o disposiciones de carácter general a que se refiere el artículo 1 de la LJCA».

En definitiva, para el Tribunal Constitucional el EPCG es una norma primaria, dotada de fuerza y valor de ley y por ello, sólo justiciable ante el propioTribunal, al igual que ocurre con los Reglamentos de las Cámaras. Por esta razón desestima el amparo, que según esta interpretación se ha interpuesto frente a una norma con rango y valor de ley, lo que en modo alguno permite el artículo 42 LOTC $^{36}$.

36 Para ser exactos habria que señalar que el amparo resuelto en esta sentencia es un amparo mixto, ya que el actor, un funcionario en activo de las Cortes Generales, había recurrido no sólo el citado Acuerdo de las Mesas del Congreso y del Senado por el que se modificaba el Estatuto, sino además la sentencia del Tri- 
A este respecto, Santaolalla ha mantenido que la solución más razonable habría sido calificar al EPCG como una norma formalmente reglamentaria, aunque procedente de las Cortes Generales, representando un reglamento independiente al no estar sometido a ninguna ley y que podría ser controlado por la Jurisdicción contencioso-administrativa en lo relativo a su respeto a la Constitución, como es la regla en este tipo de reglamentos administrativos. Esto concuerda con la referencia del artículo 58.1 LOPJ a los recursos contencioso-administrativos "contra los actos y disposiciones de los órganos de gobierno del Congreso de los Diputados y del Senado ${ }^{37}$.

Sin embargo, para el Tribunal existe una reserva formal y material en favor del Estatuto, lo que lo convierte en una norma primaria, directamente incardinada en la Constitución. Entiende, por tanto, que goza de fuerza de ley, al menos en su vertiente pasiva, por lo que ninguna otra norma puede entrar a regular la materia que le ha sido en exclusiva reservada. Pero el Tribunal va aún más lejos, al atribuir al Estatuto verdadero valor de ley, entendiéndolo susceptible de declaración de inconstitucionalidad, a pesar de que en la LOTC no existe referencia alguna en tal sentido. De hecho, elTribunal subsume al Estatuto en el artículo 27.2 b), como disposición normativa con fuerza de ley. Y como argumento adicional para reforzar su tesis sostiene que si no fuera así, esto es, si el Estatuto fuese una simple norma reglamentaria de categoria inferior a la ley, la propia reserva constitucional de ley en materia funcionarial quebraría en lo que respecta a los funcionarios al servicio de las Cortes. Por tanto, según ula estricta lógica del sistema», el Tribunal Constitucional llega a la conclusión analógica de que el Estatuto no puede ser más que una norma con fuerza y valor de ley. En este sentido, Mollinedo Chocano ha sostenido, con acierto, que este argumento conduce al absurdo de entender que cualquier norma que regule materia sometida a reserva legal, pasa automáticamente a gozar de fuerza de ley, con independencia de la con-

bunal Supremo en la que éste se declaraba incompetente para conocer del asunto, dado el rango de ley del Estatuto. Por tanto, al considerar que esta norma goza efectivamente de rango y fuerza de ley, el Tribunal Constitucional entiende que no ha existido vulneración del artículo $24 \mathrm{CE}$, como el demandante alegaba. Y precisamente por tratarse de una norma con rango y valor de ley no puede proceder a analizar las otras alegaciones, pues artículo el 42 LOTC no lo permite.

37 Derecho Parlamentario Español, op. cit,, pág. 54. En la actualidad, el artículo 58 de la LOPJ, tras la reforma efectuada por la Ley Orgánica 6/1998, de 13 de julio, hace referencia a "los actos y disposiciones de los órganos competentes del Congreso de los Diputados y del Senado". 
currencia o no en la disposición en cuestión de los rasgos definitorios esenciales de las leyes, entre ellos, su procedencia de un órgano con potestad legislativa ${ }^{38}$.

Lo que a mi juicio late detrás de esta interpretación jurisprudencial no es otra cosa que la reserva legal que el artículo 103 CE determina en relación con el estatuto de los funcionarios públicos y la necesidad de ley orgánica para la regulación de materias relativas al derecho de sindicación (artículos 81 y $53.2 \mathrm{CE}$ ). Resulta cuanto menos llamativo, que a pesar de las garantias establecidas en el texto constitucional para la regulación de estas materias, en lo que respecta a los funcionarios de las Cortes, la norma encargada de regular estas cuestiones haya sido aprobada por las Mesas, sin ningún pronunciamiento de los respectivos Plenos. Una cuestión de tanta trascendencia no se resuelve con el expediente de conceder valor de ley al Estatuto, como si de este modo se solventaran todos los problemas. El Tribunal Constitucional ha obviado la forma de elaboración de la norma y ha procedido como si se hubiera actuado conforme a la Carta Magna, esto es, efectuándose su aprobación por los órganos competentes para ello.

En conclusión, el EPCG, fruto de la potestad autonormadora de las Cortes y de su autonomía administrativa, es susceptible de control por la Jurisdicción Contencioso-administrativa según la nueva LJCA, que en su artículo 1.3.a) alude expresamente a disposiciones en materia de personal. Por el contrario, no resulta susceptible de control de constitucionalidad por el Alto Tribunal, dada la falta de mención expresa en la LOTC, junto a las demás normas fruto de la autonomía reglamentaria y debido, además, a su forma de elaboración, por las Mesas de las Cámaras en sesión conjunta, lo que impide su inclusión en el artículo 27.2 b), como norma con fuerza de ley.

\subsection{El Estatuto de Personal de las Cámaras Autonómicas}

Pero si problemas suscita la aprobación del EPCG por las Mesas del Congreso y del Senado en reunión conjunta, más complejas son las cuestiones que se plantean en relación con los referentes autonómicos de esta norma. En efecto, como ya vimos páginas atrás, única-

38 «El personal al servicio de las cámaras en la jurisprudencia constitucional -aproximación al régimen constitucional de la función pública parlamentaria - ", en Parlamento y Justicia Constitucional, op. cit., pág. 450. 
mente algunos Estatutos de Autonomía prevén la elaboración de una norma similar, por lo que en los restantes casos la cobertura legal a su creación viene dada por el Reglamento Parlamentario de cada Asamblea.

Lo cierto es que el Tribunal Constitucional no ha parecido tener en cuenta esta circunstancia y en el único pronunciamiento jurisprudencial relativo al Estatuto de Personal de una Cámara autonómica no se hace alusión a estas cuestiones. El Auto 296/85, de 8 de mayo, resuelve un amparo contra el Acuerdo de la Mesa del Parlamento de Navarra, de 15 de octubre de 1984, por el que se modificaban varios preceptos del Estatuto de Régimen y Gobierno Interior del Parlamento de Navarra, así como contra un Acuerdo desestimatorio de un recurso interpuesto contra el anterior. El Tribunal rechaza las pretensiones de los recurrentes, entendiendo que el acto impugnado tiene el carácter de disposición general, al estar integrado en un Estatuto con valor de ley, aunque emanado de la Mesa, por lo que no está comprendido en la hipótesis del artículo 42 de la LOTC. En efecto, según el órgano de defensa constitucional, el amparo previsto en esta disposición debe interponerse frente a "decisiones o actos sin valor de ley", no siendo posible la interposición de un recurso directo frente a actos con valor de ley.

En este Auto, elTribunal Constitucional llega a afirmar que la citada disposición es de carácter general, integrada en un Estatuto con valor de ley, aunque emanada de la Mesa. Por ello, no puede conceder el amparo, ya que este proceso constitucional no resulta idóneo para fiscalizar una disposición de estas características.

A pesar de no existir más pronunciamientos jurisprudenciales del Tribunal Constitucional relativos a las normas de personal de las Cámaras autonómicas, debemos pensar que ese carácter que el Tribunal concede al Estatuto navarro, como disposición con valor de ley, debe ser aplicable a las mismas normas de las restantes Asambleas autonómicas. Sobre todo, si atendemos al dato de que de esta norma no podemos predicar el rasgo de primariedad, ya que su fundamento se halla en el Reglamento Parlamentario de la Cámara y no en el Estatuto de Autonomía. En la LORAFNA ${ }^{39}$, norma institucional básica de la Comunidad Foral Navarra, no se contiene ninguna previsión al respecto. Por tanto, nos encontramos con que una norma con las pecu-

39 Ley Orgánica 13/1982, de 10 de agostó, de Reintegración y Amejoramiento del Régimen Foral de Navarra. 
liaridades del Reglamento parlamentario, competente únicamente para regular cuestiones atinentes a la organización y funcionamiento interno de la Cámara, remite a otra norma para que regule el estatuto de los funcionarios al servicio de la Asamblea. Además, como se dice en el propio pronunciamiento jurisprudencial, el Estatuto de Régimen y Gobierno Interior del Parlamento de Navarra, ha sido elaborado por la Mesa de la citada Cámara. A la vista de estos datos resulta realmente difícil compartir las tesis del Tribunal Constitucional, que dota al Estatuto de rango de ley.

Es probable que en la decisión última del Tribunal influyera el hecho de que, al momento de resolverse el recurso de amparo que venimos comentando, la Ley Orgánica del Poder Judicial, Ley 6/1985, de 1 de julio, todavia no había entrado en vigor. Esta norma iba a atribuir a la Jurisdicción Ordinaria, en concreto a la Contencioso-Administrativa, la competencia sobre los actos y disposiciones en materia de personal y administración emanados de las Cámaras legislativas, tanto centrales como autonómicas ${ }^{40}$. Si el Tribunal Constitucional en aquel momento no hubiera entendido que la citada norma era susceptible de control de constitucionalidad, no hubiera resultado posible su fiscalización jurisdiccional ante ninguna otra instancia.

Al momento de producirse este pronunciamiento jurisprudencial, en el Derecho positivo español, únicamente el articulo 35.3 del EPCG ${ }^{41}$ y por mimetismo, algunos Estatutos de Personal de Asambleas autonómicas, aludían a la competencia de la Jurisdicción Contencioso-Administrativa para controlar las reclamaciones administrativas en

40 En concreto, el artículo 58 LOPJ estableció: «La Sala de lo ContenciosoAdministrativo del Tribunal Supremo conocerá: 1. En única instancia, de los recursos contencioso-administrativos que se promuevan contra actos y disposiciones emanados del Consejo de Ministros o de sus Comisiones Delegadas, de los recursos contra actos y disposiciones procedentes del Consejo General del Poder Judicial y contra los actos y disposiciones de los órganos de gobierno del Congreso de los Diputados y del Senado, del Tribunal Constitucional, del Tribunal de Cuentas y del Defensor del Pueblo en materia de personal y actos de administración».

El artículo 74 por su parte señalaba: "La Sala de lo Contencioso-Administrativo delTribunal Superior de Justicia conocerá en única instancia: c) De los recursos contra disposiciones y actos procedentes de los órganos de gobierno de la Asamblea Legislativa de la Comunidad Autónoma y de sus Comisionados, en materia de personal y actos de administración".

41 El artículo 35.3 del EPCG de 23 de junio de 1983 estableció que "contra los Acuerdos de las Mesas que resuelvan reclamaciones administrativas en materia de personal cabrá recurso contencioso-administrativo, de conformidad con la normativa reguladora de dicha Jurisdicción». 
materia de personal interpuestas contra Acuerdos de las Mesas de las Cámaras. Pero este precepto no parece de aplicación a disposiciones de carácter general como la norma estatutaria, sino únicamente a actos singulares ${ }^{42}$.

Sin embargo, el Tribunal Supremo no ha entendido así la cuestión y es posible encontrar pronunciamientos jurisprudenciales en los que este órgano afirma que la Jurisdicción Contencioso-Administrativa deviene competente para enjuiciar el Estatuto de Personal de una Cámara autonómica. Curiosamente, los pronunciamientos aludidos hacen referencia al Estatuto de Régimen y Gobierno Interior del mismo Parlamento navarro.

En el Auto de 26 de enero de 1988, resuelve el Tribunal Supremo un recurso de apelación interpuesto por funcionarios del Parlamento de Navarra contra la desestimación de un recurso de súplica planteado contra otro Auto, sobre incompetencia para conocer de las cuestiones suscitadas contra actos emanados de la Mesa del citado Parlamento Foral. El Tribunal entiende, por un lado, que el citado Acuerdo modificatorio del Estatuto no goza del mismo tratamiento legal que el Reglamento Parlamentario de la Asamblea y el resto de leyes, en cuanto a su sometimiento a la Jurisdicción Constitucional, pues ha sido aprobado por la Mesa del Parlamento y no por los órganos que gozan de potestad legislativa. Por otro lado, entiende elTribunal Supremo que no estamos ante un acto interno de la Cámara, por lo que, en aplicación de la doctrina del Tribunal Constitucional, no hay motivos para sustraerlo al conocimiento de la cuestión, dado que el artículo 74.1.c) de la LOPJ encomienda a la Sala de lo Contencioso-Administrativo de los Tribunales Superiores de Justicia el conocimiento en única instancia de los recursos de esta clase que se interpongan contra actos y disposiciones procedentes de los órganos de gobierno de la Asamblea Legislativa de la Comunidad Autónoma, precisamente, en materia de personal.

En el Auto del Tribunal Supremo de 10 de octubre de 1989, se resuelve una cuestión similar, referida también a una modificación del Estatuto de Régimen y Gobierno Interior del Parlamento navarro. ElTri-

42 A este respecto, hay que señalar que el Estatuto de Personal no es norma apropiada para contener la atribución de competencia sobre determinada clase de actos a la Jurisdicción Ordinaria. Únicamente una ley orgánica (Ley Orgánica del Poder Judicial, según el artículo $117 \mathrm{CE}$ ) puede efectuar una atribución de este calibre. 
bunal vuelve a reiterar los argumentos reflejados en el Auto anterior, aunque en esta ocasión añade uno nuevo de gran relevancia. Se destaca cómo el Estatuto de esta Cámara no puede asimilarse al EPCG, dado que éste es una norma primaria, incardinada directamente en la Constitución, mientras que la norma que se cuestiona no tiene punto de conexión con la LORAFNA, sino que deriva del Reglamento del Parlamento de Navarra (artículos 66, 67.1 y disposición adicional 4. ${ }^{9}$ ).

Estos pronunciamientos han debido de tener su influencia sobre los Tribunales de lo Contencioso, ya que, en la Sentencia del Tribunal Supremo de 29 de diciembre de 1990, si bien se dilucida una cuestión atinente a una modificación del Estatuto de Régimen y Gobierno Interior del Parlamento de Navarra, la causa ya no estriba en la falta de conocimiento del asunto por los tribunales inferiores. Por el contrario, el Tribunal Superior de Justicia de Navarra había estimado un recurso interpuesto por varios funcionarios de dicha Cámara contra un acuerdo de la Mesa del Parlamento que modificaba un precepto del citado Estatuto.

La jurisprudencia del Tribunal Supremo no sólo supone que los Tribunales de lo Contencioso pueden controlar la regularidad del Estatuto de Cámaras autonómicas, al menos en tanto hayan sido aprobados por órganos carentes de potestad legislativa, sino que ha provocado la reacción del propio Parlamento navarro. En efecto, el nuevo texto reglamentario en vigor, de 2 de febrero de 1995, contiene una disposición que concede al Estatuto del Personal del Parlamento navarro, fuerza de Ley Foral ${ }^{43}$. Las consecuencias que cabe extraer de esta declaración son relevantes. Para empezar, la LORAFNA, norma institucional básica de la Comunidad Foral Navarra, no contiene ninguna previsión al respecto. Por tanto, nos encontramos con que una norma con las peculiaridades del Reglamento parlamentario, no sólo remite a otra para que regule el estatuto de los funcionarios al servicio de la Asamblea, sino que además la eleva a la categoría de Ley Foral, con las consecuencias que ello conlleva. Es del todo evidente que desde el punto de vista del sistema de fuentes del Derecho no es admisible que el Reglamento parlamentario conceda fuerza de Ley foral al Estatuto de personal de la Cámara. Únicamente el propio Esta-

43 La Disposición Adicional Tercera de esta norma dispone en su apartado primero que «los derechos, deberes, situaciones, funciones y competencias del personal al servicio del Parlamento serán los determinados en el Estatuto del Personal del Parlamento de Navarra, que será aprobado mediante una disposición con fuerza de Ley Foral's. 
tuto de Autonomía está legitimado para efectuar una declaración de este tipo.

Ahora, únicamente resta esperar a ver qué ocurriría si un precepto estatutario fuera llevado ante la Jurisdicción Contenciosa. Debe quedar claro que losTribunales de lo Contencioso no están vinculados por esta declaración del Reglamento parlamentario, efectuada, además, al margen de su competencia propia.

Tampoco es fácil especular sobre la postura que hoy adoptaría el Tribunal Constitucional en lo referente a estas cuestiones. Como hemos visto, contamos únicamente con un pronunciamiento relativo al EPCG y otro en torno al Estatuto de una Cámara autonómica. A mi juicio, el cambio de circunstancias operado desde entonces en lo referente al sometimiento a control jurisdiccional de los actos de administración y personal de las Asambleas legislativas, así como la evolución detectada en la jurisprudencia constitucional relativa al conocimiento de disposiciones de carácter general a través del recurso de amparo, permite apuntar ciertas hipótesis.

\section{UN POSIBLE CAMBIO DE CONCEPCIÓN JURISPRUDENCIAL}

Resulta conveniente hacer referencia a una cuestión que podría provocar un cambio en la concepción jurisprudencial delTribunal Constitucional en torno al rango y control que sobre la norma estatutaria de personal cabe ejercer. En efecto, puede apreciarse en la doctrina del Alto Tribunal una evolución notable, que parte de un entendimiento bastante amplio de lo que debia entenderse por normas susceptibles de fiscalización a través de los procedimientos de control de constitucionalidad y que culmina con una posición más estricta del Tribunal a la hora de apreciar esta circunstancia.

Ciertamente, la jurisprudencia constitucional relativa al control de las disposiciones de carácter general ha sufrido un giro gradual. $\mathrm{Si}$ durante años, el Tribunal Constitucional consideró que las disposiciones de carácter general emanadas de las Asambleas Legislativas eran únicamente impugnables a través de los procedimientos de declaración de inconstitucionalidad, en la actualidad, el órgano de defensa constitucional sostiene que dichas disposiciones, si carecen de valor de ley, son susceptibles de fiscalización únicamente mediante recurso de amparo. 
Esta doctrina a la que aludimos ha sido elaborada gracias al control que el Tribunal Constitucional se ha visto llamado a efectuar sobre las Resoluciones de los órganos rectores de las Cámaras parlamentarias dictadas con el objeto de interpretar o suplir los diversos Reglamentos parlamentarios.

ElTribunal Constitucional fue durante años proclive a asimilar al Reglamento parlamentario las disposiciones de las Cámaras emanadas de sus órganos rectores con el fin de interpretar o suplir la propia norma reglamentaria. En consecuencia, el control que sobre estas Resoluciones, verdaderas normas jurídicas de carácter general, cabía ejercer era el propio de los procesos de control de constitucionalidad. En concreto, esta línea argumental se inaugura en 1984, con el Auto 183/84, de 21 de marzo, que marcará toda una doctrina que habría de continuar inalterada durante varios años. En este pronunciamiento, el Tribunal Constitucional entiende que la Resolución impugnada, supletoria del Reglamento, es una norma y como tal, no puede ser objeto de un recurso de amparo. Algo más tarde, en el Auto 244/86, de 12 de marzo, el Tribunal Constitucional de forma explícita mantiene que las Resoluciones, en cuanto que normas de carácter general que producen los mismos efectos que el propio Reglamento parlamentario, constituyen normas con valor de ley, susceptibles únicamente de fiscalización a través de los procedimientos de control de la constitucionalidad establecidos al efecto por la Constitución y la LOTC.

Pero a partir de la STC 118/88, de 20 de junio, el Tribunal comienza progresivamente a matizar su doctrina y es más riguroso a la hora de afirmar que una determinada Resolución de carácter general es susceptible de control de constitucionalidad. Estos cambios se acentúan aún más con la STC 119/90, de 21 de junio. Pero el abandono definitivo de su postura no se produce hasta la STC 44/95, de 13 de febrero. Tras este pronunciamiento, las Resoluciones emanadas de los órganos rectores de las Cámaras se consideran susceptibles de control únicamente a través del recurso de amparo, a pesar de que constituyen verdaderas disposiciones de carácter general, que entran a formar parte, de manera permanente, del ordenamiento parlamentario de la Cámara en cuestión ${ }^{44}$.

44 A este respecto, véase Morales ArRoYo, J. M., "Un avance en la jurisprudencia constitucional sobre las resoluciones parlamentarias", Revista Española de Derecho Constitucional, 46 (1996). También puede consultarse: MATIA PORTILLA, E., "La insatisfactoria jurisprudencia del Tribunal Constitucional sobre las llamadas normas interpretativas y supletorias del Reglamento Parlamentarion, 
Esta nueva línea argumental del Alto Tribunal creo que puede influir en la postura que el órgano de defensa constitucional ha venido manteniendo en los escasos pronunciamientos relativos al control de los Estatutos de Personal de las diversas Asambleas legislativas. En efecto, si en un primer momento el Tribunal Constitucional parecia entender que el control de las disposiciones de carácter general le correspondía efectuarlo a él mismo, mediante los procedimientos de declaración de constitucionalidad, hoy día parece tener más claro que disposición general y valor de ley son conceptos que no siempre se presuponen mutuamente. Por ello, en el momento actual, el Tribunal Constitucional cuenta en su propia doctrina con más elementos que le permitirían, como primer paso, replantearse la atribución de rango o valor de ley a la norma estatutaria, y una vez hecho esto, reconsiderar el problema de las vías para su control ${ }^{45}$.

Puedo entender que el carácter de norma primaria del EPCG dificulta bastante su caracterización como norma infralegal, a pesar del procedimiento de elaboración que se ha seguido, a mi entender, al margen de lo que el propio texto constitucional demanda. A pesar de esto, parece más acertado defender su sometimiento a la Jurisdicción Contencioso-Administrativa.

Corts. Anuario de Derecho Parlamentario, 7 (1999); De Alfonso Pinazo, C., “El tratamiento del Tribunal Constitucional de las denominadas normas interpretativas $y$ supletorias del Reglamento Parlamentario", en PAU I VALL (coord.), Parlamento y Justicia Constitucional (Pamplona, Aranzadi, 1997); PAU I VALL, F., "La sumisión a Derecho de los criterios interpretativos y las normas supletorias", Revista de las Cortes Generales, 25 (1992).

45 De hecho, podría pensarse que este replanteamiento ya se ha producido, ya que existe un pronunciamiento jurisprudencial posterior, la STC 121/97, de 18 de julio, en el que parece resolverse la impugnación en amparo de varios preceptos del EPCG. Pero lo cierto es que esta sentencia no es indicativa, ya que no queda nada claro la actividad parlamentaria realmente cuestionada. Nos encontramos, por un lado, con un Acuerdo de las Mesas del Congreso y del Senado adoptado de forma conjunta el 25 de abril de 1988, por el que se daba nueva redacción a los artículos 23 y 24 del EPCG; por otro, una Resolución conjunta de los Presidentes del Congreso de los Diputados y del Senado por la que se dictan Normas Reguladoras de las elecciones a la Junta de Personal de las Cortes Generales, dictada el mismo 25 de abril. Aunque el Tribunal Constitucional se pronuncia expresamente sobre la idoneidad del recurso de amparo para impugnar normas de carácter general y en ningún momento sostiene que se está utilizando una via procesal inadecuada, las conclusiones que podemos extraer debemos analizarlas con precaución, dado que podría defenderse que la actividad parlamentaria realmente cuestionada es la Resolución de los Presidentes de ambas Cánıaras y no el Acuerdo conjunto de las Mesas que modificaba el citado EPCG. 
El caso de los Estatutos de Personal de las Cámaras autonómicas, en aquellos casos en los que su elaboración aparece prevista en el Reglamento Parlamentario de la Asamblea en cuestión, es diferente. No creo que al Tribunal Constitucional le resultara difícil rectificar su anterior postura y defender que se trata de una disposición de carácter general aunque de rango infralegal, ya que si rango de ley tiene la norma reglamentaria que prevé su elaboración, no podemos predicar la misma cualidad del Estatuto. En los casos en los que, además, su elaboración haya sido llevada a cabo por la Mesa de la Cámara pertinente, este argumento se refuerza y resulta todavía más lógico defender su control por la Jurisdicción Ordinaria.

\section{CONCLUSIONES}

Si bien entiendo, al igual que el Tribunal, que dada la reserva de Estatuto que se desprende de la Constitución y del carácter de norma primaria que ello comporta, puede predicarse su fuerza de ley, no comparto sin embargo la opinión de que su rango se debe además a la reserva legal existente en materia de función pública. Es evidente que, ateniéndonos a una interpretación sistemática del texto constitucional, tiene lógica atribuir fuerza de ley al Estatuto, pues es imposible desvincularse de la reserva legal que el artículo 103 de la Constitución establece en materia de funcionarios. Pero ese carácter sería posible predicarlo del Estatuto en cuanto norma aprobada "por las Cámaras" y no por las Mesas, órganos rectores pertenecientes a la Administración parlamentaria.

Pero donde verdaderamente creo que se equivoca el Tribunal es al entender que tiene competencia para enjuiciar la constitucionalidad de aquél. A mi juicio, como ya he señalado, de la LOTC no puede desprenderse la idea de que sea susceptible de tal control. Si el legislador ha optado por incluir referencias expresas al Reglamento de las Cámaras y al de las Cortes Generales, no se entiende el porqué de la omisión del Estatuto, si su voluntad era la de someterlo igualmente al control del Tribunal Constitucional. En este punto el Tribunal se ha extralimitado, arrogándose una función que no le compete y pasando por encima de la voluntad del legislador. En efecto, el artículo 27 LOTC recoge una enumeración de las disposiciones susceptibles de control de constitucionalidad a modo de enumeración cerrada, de numerus clausus. 
Además, si atendemos al modo en que el Estatuto ha sido aprobado, por el acuerdo de dos órganos de las Cámaras, pero no por éstas en Pleno, cómo sería lo deseable y dada la reserva legal en materia de Función Pública, lo más coherente es defender que la Jurisdicción Contencioso-administrativa debe ser la encargada de su control. Aplicando la doctrina del ultra vires, del mismo modo que se ha aplicado a los Decretos Legislativos y a los reglamentos administrativos sin cobertura legal, no hay duda de que el Estatuto, en cuanto que norma aprobada por las Mesas, es susceptible de control por la Jurisdicción ordinaria, puesto que no cumple con la exigencia constitucional que impone su aprobación por las Cámaras. Por tanto, no es posible predicar de esta norma el rango de ley que justificaria su sometimiento a la Jurisdicción Constitucional.

En lo que respecta a los Estatutos de Personal de los Parlamentos autonómicos, habría que hacer varias precisiones. En primer lugar, no es posible predicar el carácter de norma primaria de aquellos Estatutos cuya previsión se encuentra en el Reglamento de la misma Asamblea. Es evidente que en estos casos la norma de personal debe ajustarse, además de al texto constitucional y al Estatuto de Autonomía, al propio Reglamento Parlamentario que ha previsto su aprobación.

En segundo lugar y en lo que respecta al procedimiento de elaboración, debemos diferenciar según hayan sido aprobados por el Pleno, por una Comisión o por las respectivas Mesas. En el primer caso, no hay nada que objetar. Sería lo deseable en todos los supuestos y no provoca problemas a la hora de afirmar su sometimiento a la Jurisdicción Constitucional y su cumplimiento formal y material de la reserva de ley ${ }^{46}$. En el caso de aprobación por una Comisión no creo que existan inconvenientes para afirmar su rango de ley y por tanto, su sometimiento a la Jurisdicción delTribunal Constitucional, en la medida en que se entiende que funcionan con competencia legislativa plena, delegada (expresa o tácitamente) por el Pleno de la Cámara. En cambio, en lo que hace a los Estatutos aprobados por las Mesas de sus Cámaras respectivas, reiterar lo que ya he mencionado en relación con el EPCG. En efecto, a pesar de que en ocasiones ha sido el propio Reglamento de la Cámara autonómica el que ha encomendado esta tarea a la Mesa de la Asamblea, esto no obsta para que sea excesivo

46 El Estatuto de la Diputación General de La Rioja ha sido aprobado por el Pleno, como el artículo 141 del Reglamento de esa Cámara había previsto. 
atribuir rango y valor de ley a una norma aprobada por un órgano perteneciente a la Administración Parlamentaria ${ }^{47}$. Por tanto, entendemos que su control, al igual que en el caso del EPCG, debería corresponder a la Jurisdicción contencioso-administrativa.

Por último, en todos aquellos casos de insuficiencia de rango de la norma estatutaria, sea en virtud del modo de producción o de la falta de carácter primario, surge el problema del incumplimiento constitucional de la reserva de ley para las cuestiones relativas al estatuto de la función pública.

47 Éste es el caso, por ejemplo, de las Cortes de Castilla y León, cuyo Reglamento dispone en la Disposición Final Tercera que la uelaboración, aprobación y modificación" del Estatuto corresponde a la Mesa. 